\title{
PECULIARITIES OF MASS-EXCHANGE PROCESSES IN ANAEROBIC GAS-LIQUID MEDIA
}

\author{
A. Shevchenko, A. Sokolenko, I. Vinnichenko, K. Vasylkivsky \\ National University of Food Technologies
}

\begin{tabular}{l} 
Key words: \\
Gas-liquid medium \\
Gas-holding ability \\
Mass transfer \\
Carbon dioxide \\
Solubility \\
Circulating contour \\
\hline
\end{tabular}

Article history:

Received 13.09.2018

Received in revised form

01.10 .2018

Accepted 22.10.2018

Corresponding author:

A. Shevchenko

E-mail:

npnuht@ukr.net

\begin{abstract}
The paper deals with the peculiarities of mass-exchange processes in anaerobic gas-liquid culture media, in which the formation of a dissolved and dispersed $\mathrm{CO}_{2}$ gas phase is the result of fermentation of sugars with the final result of the synthesis of ethyl alcohol. The material balance of such transformations corresponds to the Gay-Lussac equation. The formed $\mathrm{CO}_{2}$ must enter the total flow to participate in the processes of carbon cycle. The latter relate to pressures in the gas phase of sealed vehicles, the potential of a swollen gas-liquid medium, the kinetic energy of circulation circuits, and potentials for gradients of saturation under hydrostatic pressures. The manifestation of the properties of a field in the form of hydrostatic pressure and power indices in accordance with the Archimedes law in this study is used to determine the motive factor in the creation of vertical circulatory contours. At the heart of such proposal lies the third law of the Newton, according to which for the regime of steady motion the equality of Archimedes forces and the forces of resistance of the medium are taken. The system with the self-generating of the gas phase in the full volume of the culture medium results in a growing gas-holding capacity in height, which, in turn, provides a growing energy potential. This means the presence of not only a full-circle vertical circular contour, but also the existence of lowerdimensional layers of contours.
\end{abstract}

The influence of geometrical parameters on the gasholding capacity of media which correspond to the dependencies that are presented in the article is also presented. On the basis of the established regularities and phenomenological generalizations, the role of circular circuits for partial desaturation is shown as well as the creation of zones of non saturation of the liquid phase, which ensures the possibility of lowering the resistance of mass transfer on $\mathrm{CO}_{2}$. The implementation of technical measures in the form of alternating pressures in the gas phase (and even in the full volume of the medium) is proposed to create periods of desaturation and possible saturation. The result of such changes is the possibility of processing medium with a high initial concentration of sugars and an increased final concentration of ethyl alcohol.

DOI: $10.24263 / 2225-2924-2018-24-5-16$ 


\title{
ОСОБЛИВОСТІ МАСООБМІННИХ ПРОЦЕСІВ В АНАЕРОБНИХ ГАЗОРІДИННИХ СЕРЕДОВИЩАХ
}

\author{
О.Ю. Шевченко, А.І. Соколенко, І.М. Вінніченко, К.В. Васильківський \\ Національний університет харчових технологій
}

У статті описано особливості масообмінних процесів в анаеробних газорідинних культуральних середовищах, в яких утворення розчиненої $і$ диспергованої газової фази $\mathrm{CO}_{2}$ є наслідком зброджування иукрів з кінцевим результатом синтезу етилового спирту. Матеріальний баланс таких перетворень відповідає рівнянню Гей-Люссака, за яким майже половина маси иукру витрачається на утворення інертного газу - діоксиду вуглецю, хімічна формула якого означає відсутність потениіалу хімічної енергії. Надалі утворений $\mathrm{CO}_{2}$ має увійти в загальний потік для участі в процесах колообігу вуглецю. Однак умови ендогенного синтезу вуглещю в культуральних середовищах призводять до додаткових проявів з енергетичними ефектами. Останні стосуються тисків у газовій фазі герметизованих апаратів, потенціалів набухлого газорідинного середовища, кінетичної енергії ииркуляиійних контурів і потенціалів за градієнтами насичення в умовах гідростатичних тисків. Названі енергетичні прояви мають місие після досягнення станів насичення рідинної фази $\mathrm{CO}_{2}$ від моменту утворення диспергованої газової фази, що супроводжується відповідними рівнями диспергованої газової фази у формі газових бульбаток. Прояв властивості гравітаиійного поля у формі гідростатичного тиску $i$ силових показників відповідно до закону Архімеда в иьому дослідженні використано для визначення рушійного фактора у створенні вертикальних ичикуляиійних контурів. В основі такої пропозиції лежсить третій закон Ньютона, за яким для режсиму усталеного руху прийнято рівність сил Архімеда $і$ сил опору середовища. Це ж припущення підтверджсється і в умовах перехідних прочесів.

Система із самогенеруванням газової фази в повному об'ємі культурального середовища приводить до зростаючої по висоті газоутримувальної здатності, яка, у свою чергу, забезпечує зростаючий енергетичний потенціал. Це підтверджує існування не лише повнооб'ємного вертикального ичикуляційного контуру, а й існування пошарових контурів менших масштабів.

Також наведені залежності, яким відповідають впливи геометричних параметрів на газоутримувальну здатність середовищ. На основі встановлених закономірностей і феноменологічних узагальнень показано роль циркуляційних контурів для часткової десатуращії $і$ створення зон ненасичення рідинної фази, що забезпечує можливість зниження опору масопередачі по $\mathrm{CO}_{2}$. Запропоновано виконання технічних заходів у формі змінних тисків у газовій фазі (а отже, і в повному об'ємі середовища) для створення періодів десатураиії і можливої сатурації. Наслідком таких змін може бути переробка середовищ із підвищеною початковою конщентрацією иукрів $і$ підвищеною кінцевою кониентрацією етилового спирту.

Ключові слова: газорідинне середовище, газоутримувальна здатність, масопередача, діоксид вуглецю, розчинність, ииркулящійний контур. 
Постановка проблеми. Швидкість перебігу технологічних процесів значною мірою визначається їх термодинамічними параметрами, фізичними властивостями рідинних і газових фаз, наявністю або відсутністю фазових переходів, співвідношеннями рушійних параметрів і параметрів опору масопередачі тощо.

Енергетичний рівень середовищ аеробного й анаеробного бродіння визначається показниками таких полів, як гравітаційне, теплове, гідростатичне, що доповнюється розчиненою і диспергованою газовими фазами. 3 точки зору інтересів інтенсифікації масообмінних процесів певним узагальненням може слугувати гідродинамічний стан газорідинного середовища, який, у свою чергу, визначається газоутримувальною здатністю. Це стосується як аеробних, так і анаеробних процесів. У першому випадку газова фаза складається переважно з азоту й кисню в складі аераційного повітря з додаванням синтезованого $\mathrm{CO}_{2}$, а в другому - виключно 3 діоксиду вуглецю [1-3].

Наявність диспергованої газової фази означає збільшення загального об'єму середовища, що відповідає певному рівню потенціальної енергії $\mathrm{i}$, одночасно, кінетичної енергії у зв'язку з виникненням замкнутих циркуляційних контурів. Останнє є відгуком систем на єдність проявів закономірностей гравітаційного поля і закону Архімеда, в яких у загальних випадках формуються механічні впливи у формі ударів, зсувів, вібрацій, гомогенізації середовищ, трансформації потенціальної енергії у кінетичну, теплову або енергетичні накопичення [4-6]. Акустичні впливи у формі квазіпружних коливань у сукупності рідинної і газової фаз супроводжуються ефектами акустичних хвиль і турбулентності, кавітації, кумулятивними явищами, автоколиваннями, капілярними ефектами, сонолізом тощо [7; 8].

Анаеробні і аеробні мікробіологічні процеси подібні за зовнішніми фізичними ознаками, однак з точки зору порівняння першопричин їх енергетичного забезпечення вони помітно відрізняються. Вхідний енергетичний потенціал анаеробних процесів представлений хімічною енергією розчинів цукрів, який під дією дріжджів трансформується в хімічну енергію спирту, енергію хімічних трансформацій і теплову енергію у відомому за Гей-Люссаком ланцюгу:

$$
\mathrm{C}_{6} \mathrm{H}_{12} \mathrm{O}_{6}=2 \mathrm{C}_{2} \mathrm{H}_{5} \mathrm{OH}+2 \mathrm{CO}_{2} \uparrow
$$

3 відповідним енергетичним балансом:

$$
2870=(2640+61)+169, \text { кДж, }
$$

записаним для одного моля глюкози [9].

За відсутності заперечень щодо записаних відображень матеріального i теплового балансів умовами (1) і (2) виникає необхідність пояснити наявність енергетичних потенціалів газорідинних середовищ у формі потенціальної енергії набухлого шару і кінетичної енергії циркуляційних контурів. Самогенерування $\mathrm{CO}_{2}$ відбувається в повному об'ємі середовища, а показники газових потоків визначаються динамікою бродіння.

Метою дослідження $є$ аналіз фізичного підгрунтя для пошуків новітніх засобів інтенсифікації масообмінних процесів у газорідинних анаеробних середовищах. 
Методи дослідження. Використані феноменологічні узагальнення на основі відомих законів природи з математичною формалізацією взаємозв'язків між гідродинамічними, геометричними і термодинамічними параметрами середовищ.

Викладення основних результатів дослідження. Наближаючись до показників промислових технологій 3 орієнтиром кінцевого накопичення $\mathrm{C}_{2} \mathrm{H}_{5} \mathrm{OH}$ у кількості $8 \%$ об., приходимо до висновку про початкову масову концентрацію цукрів у $160 \mathrm{\kappa г} / \mathrm{M}^{3}$. Якщо цикл зброджування складає 72 год, то середній показник динаміки зменшення концентрації цукру у $1 \mathrm{~m}^{3}$ складе:

$$
\frac{d m_{\text {щ }}}{d t}=160: 72=2,222 \text { кг/год. }
$$

Оскільки зброджування кожного кг цукру супроводжується синтезом $\mathrm{CO}_{2}$ в кількості:

$$
m_{\mathrm{CO}_{2}}=\frac{1000 \cdot 88}{180}=488,9 \Gamma=0,4889 \text { кг, }
$$

де 180 - молекулярна маса глюкози; 88 - подвоєна молекулярна маса діоксиду вуглецю. Тоді щогодини в $1 \mathrm{~m}^{3}$ середовища буде синтезовано $\mathrm{CO}_{2}$ у кількості:

$$
m_{\mathrm{CO}_{2}}=0,4889 \frac{d m_{\text {щ }}}{d t}=0,4889 \cdot 2,222=1,086 \text { кг. }
$$

Оскільки енергетичний потенціал газової фази в надрідинному об'ємі визначається добутком його тиску на об'єм і він генерується в об'ємі рідинної фази, то будемо вважати, що той потенціал у загальних оцінках належить системі. Його величина складе:

$$
\begin{aligned}
& E_{\text {синт. }}=P V \mathrm{CO}_{2}=m_{\mathrm{CO}_{2}} R T=0,086 \cdot 189 \cdot 303= \\
& =62134,7 \text { Дж }=62,1347 \text { кДж/ } \mathrm{m}^{3} \text {, }
\end{aligned}
$$

де $R$ - універсальна газова стала.

Тоді за весь цикл бродіння маємо:

$$
E_{\text {синт.ц. }}=72 E_{\text {синт. }}=4474,6 \text { кДж } / \mathrm{M}^{3} .
$$

Синтезований $\mathrm{CO}_{2}$, як і його потенціал, розподіляється на дві частини. Друга 3 них стосується розчиненого газу, максимальна кількість якого відповідає стану насичення рідинної фази відповідно до закону Генрі:

$$
c_{\mathrm{H}}=k P,
$$

де $c_{\mathrm{H}}$ - гранична концентрація розчиненого $\mathrm{CO}_{2}$, кг $/ \mathrm{M}^{3} ; k-$ константа Генрі, кг/(м³ Па); $P$ - парціальний тиск газової фази, Па.

Газова фаза за межею розчинності утворює диспергований масив газових бульбашок, який відповідно до закону Архімеда долає бар'єр рідинної фази і переходить у надрідинний газовий об'єм зі збільшенням тиску в останньому, якщо апарат є герметизованим. За іншої умови діоксид вуглецю передається у відповідні збірники або в атмосферу. Процес спливання диспергованої газової фази означає наявність силової взаємодії між нею і рідинною фазою. 
Якщо мати інформацію про газоутримувальну здатністю, то це означає можливість оцінювати сумарну силову дію у створенні циркуляційних контурів. За випадків герметизованих бродильних апаратів у технологіях вторинного зброджування виноматеріалів або в інших випадках динаміка зміни тиску $P$ в газовому об'ємі відображує закономірності бродіння в системі. Так, кількість синтезованого $\mathrm{CO}_{2}$, що знаходиться в надрідинному об'ємі, визначається залежністю:

$$
m_{\mathrm{CO}_{2}}=\frac{P V_{\mathrm{\Gamma}}}{R T},
$$

де $V_{\text {г }}$ - об'єм газової фази, а кількості розчиненого $\mathrm{CO}_{2}$ відповідає умова:

$$
m_{\mathrm{CO}_{2}}^{\prime}=k P V_{\mathrm{p}},
$$

де $V_{\mathrm{p}}$ - об'єм рідинної фази в середовищі, якщо знехтувати гідростатичним тиском.

Урахування останнього приводить до рівняння виду:

$$
m_{\mathrm{CO}_{2}}^{\prime}=k\left(P+\rho g \frac{H}{2}\right) V_{\mathrm{p}},
$$

де $\rho$ - питома маса рідинної фази, кг/м ${ }^{3} ; g-$ прискорення вільного падіння, $\mathrm{м} / \mathrm{c}^{2} ; H$ - висота рідинного шару, м.

Наявності третьої складової газової фази відповідає газоутримувальна здатність $u$ у формі об'єму $\mathrm{CO}_{2}$, що одномоментно знаходиться в середовищі. Ця частина диспергованої газової фази знаходиться під дією тиску в надрідинній газовій фазі i, одночасно, гідростатичного тиску, тому його маса визначається залежністю:

$$
m_{\mathrm{CO}_{2}}^{\prime \prime}=\frac{u}{R T}\left(P+\rho g \frac{H}{2}\right), \text { кг. }
$$

Сумарна рушійна сила, що діє на дисперговану газову фазу в об'ємі газоутримувальної здатності, визначається за законом Архімеда:

$$
S_{\text {руш. }}=g \rho u, \mathrm{H} \text {. }
$$

Одночасно показник газоутримувальної здатності визначає рівень потенціальної енергії набухлого шару середовища, оскільки приріст його висоти становить:

$$
\Delta H=u / F, \mathrm{M},
$$

де $F$ - площа поперечного перерізу середовища, ${ }^{2}$.

Енергетичний потенціал від дії $S_{\text {руш. }}$ становить:

$$
E_{\text {пот. }}=\rho g u \frac{\Delta H}{2}, \text { Дж. }
$$

Особливістю середовищ анаеробного бродіння є практично рівномірний масовий синтез $\mathrm{CO}_{2}$ в усіх їх локальних зонах. Це призводить до нерівномірного розподілу диспергованої газової фази у вертикальному напрямку (рис. 1). 
Якщо в першому наближенні вважати, що швидкість спливання диспергованої газової фази не змінюється по висоті, то для виділених зон 1, 2, 3 і 4 записуємо:

$$
u=u_{1}+u_{2}+u_{3}+u_{4},
$$

де $u_{1}, u_{2}, u_{3}$ і $u_{4}$ - газоутримувальні здатності відповідних зон.

Очевидно, що для кожної із зон маємо можливість записати:

$$
S_{1 \text { руш. }}=g \rho u_{1}<S_{2 \text { руш. }}=g \rho u_{2}<S_{\text {зруш. }}=g \rho u_{3}<S_{4 \text { руш. }}=g \rho u_{4} .
$$

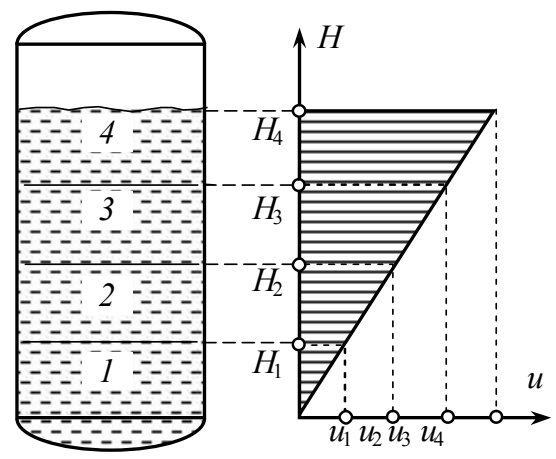

Рис. 1. Схема визначення висотного розподілу газоутримувальної здатності за показником генерування $\mathrm{CO}_{2}$

3 останнього випливає, що повисотна гідродинаміка середовища відчутно змінюється, зростаючи за показником інтенсивності з висотою. Лінійне зростання газоутримувальної здатності в системі відліку висоти Н означає таке ж лінійне зростання рушійної сили, яка через дисперговану газову фазу передається на рідинне середовище. При цьому змінний характер газоутримувальної здатності у випадку анаеробного бродіння має подвійну основу. Перша 3 них стосується повнооб'ємного самогенерування газової фази (умова (16)), а друга пов'язується зі зменшенням гідростатичних тисків у міру спливання газових бульбашок. Важливо, що вплив гідростатичного тиску також відповідає лінійному закону, однак зростання об’ємів диспергованої газової фази в ізотермічному процесі іï розширення є нелінійним і відображується залежностями:

$$
P_{\text {г.. }} u_{i}=\text { const } ; \quad \Delta u_{4-1}=u_{1} \frac{P_{\text {r... } 1}}{P_{\text {r... } 4}},
$$

де $\Delta u_{4-1}$ - приріст газоутримувальної здатності на ділянці $1-4$ за рахунок співвідношень гідростатичних тисків $P_{\text {г.с.1 }}$ і $P_{\text {г.с.4 }}$.

Робота розширення синтезованої газової фази в процесі їі розширення в межах від середнього значення гідростатичного у сумі з тиском в газовій фазі до значення тиску в газовій фазі визначається за формулою:

$$
\ell=\left(P_{\text {r.c. }}+P_{0}\right) u \ln \frac{P_{\text {r.c. }}+P_{0}}{P_{0}} .
$$


У наведених співвідношеннях (13)-(19) газоутримувальна здатність виступає в ролі визначального параметра, який, у свою чергу, залежить від швидкості генерування $\mathrm{CO}_{2}$, швидкості спливання газових бульбашок і геометричних параметрів газорідинного шару. Час перебування кожної газової бульбашки в середовищі залежить від фізико-хімічних властивостей останнього і визначається залежністю:

$$
t_{(\mathrm{\kappa})}=h / w, \mathrm{c},
$$

де $h$ - висота газорідинного шару, м; $w$ - швидкість спливання газової фази.

Тоді газоутримувальна здатність визначається умовою:

$$
u=\frac{1}{\rho_{\mathrm{CO}_{2}}} \cdot \frac{d m_{\mathrm{CO}_{2}}}{d t} t_{(\mathrm{\kappa})}=\frac{1}{\rho_{\mathrm{CO}_{2}}} \cdot \frac{d m_{\mathrm{CO}_{2}}}{d t} \cdot \frac{h}{w}, \mathrm{M}^{3} .
$$

Ситуація при оцінці системи ускладнюється тим, що і швидкість спливання газової фази, і висота газорідинного шару також залежать від газоутримувальної здатності. Однак феноменологічні міркування приводять до висновку, що $h$ i $w$ зростають зі збільшенням останньої. Якщо прийняти гіпотезу про існування такого подвійного впливу, то подальші перетворення продовжимо у формі:

$$
\begin{gathered}
h=h_{\text {рід. }}+\frac{u}{F} ; \quad u=\frac{1}{\rho_{\mathrm{CO}_{2}} w} \cdot \frac{d m_{\mathrm{CO}_{2}}}{d t}\left(h_{\text {рід. }}+\frac{u}{F}\right)= \\
=\frac{h_{\text {рід. }}}{\rho_{\mathrm{CO}_{2}} w} \cdot \frac{\frac{d m_{\mathrm{CO}_{2}}}{d t}}{1-\frac{1}{\rho_{\mathrm{CO}_{2}} w F} \cdot \frac{d m_{\mathrm{CO}_{2}}}{d t}} .
\end{gathered}
$$

Остання залежність підтверджує вплив геометричних параметрів середовища у співвідношеннях $V_{\text {рід. }}, h_{\text {рід. }}$ i F на величину газоутримувальної здатності. Видно, що за інших рівних умов при оцінці ізооб'ємних середовищ у відповідних співвідношеннях $h_{\text {рід. }}$ i F зростання комплексу $h_{\text {рід. }} / F$ приводить до збільшення газоутримувальної здатності. Одночасно це означає збільшення силової взаємодії між газовою і рідинною фазами, енергетичного потенціалу набухлого шару, кінетичної енергії циркуляційних контурів тощо. Доцільність використання бродильної апаратури зі збільшеними значеннями співвідношення $h_{\text {рід. }} / F$ знайшла своє відображення в сучасних циліндроконічних апаратах для зброджування пивного сусла. Очевидно, що наведені в цьому дослідженні залежності відповідають процесам у зброджуваних середовищах з позитивним впливом гідростатичних тисків на розчинність і накопичення $\mathrm{CO}_{2}$ в рідинній фазі. Однак для технологій анаеробного бродіння в галузі синтезу $\mathrm{C}_{2} \mathrm{H}_{5} \mathrm{OH}$ підвищення розчинності $\mathrm{CO}_{2}$ не слід оцінювати позитивним наслідком, оскільки це призводить до обмеження інтенсивності масообміну по діоксиду вуглецю між дріжджовими клітинами і рідинною фазою середовища. 3 точки зору оцінки усталеного режиму бродіння наяв- 
ність диспергованої газової фази і відповідна їх газоутримувальна здатність мають, як було показано, вирішальне значення, оскільки саме вони забезпечують існування циркуляційних контурів поряд 3 часткою циркуляції, що створюється різницею температур між середовищем і системою охолодження. Збільшення висоти рідинного шару i, відповідно, гідростатичного тиску призводить до зростаючих градієнтів концентрації розчиненого $\mathrm{CO}_{2}$, що навіть без додаткових технічних надбудов спричиняе самопливну повисотну циркуляцію. Останнє, крім раніше зазначених позитивів, супроводжується важливим ефектом дестабілізації станів насичення рідинної фази діоксидом вуглецю. Перехідний процес від початку бродіння продовжується до моменту насичення рідинної фази, який перш за все досягається для верхніх шарів практично під впливом тиску в газовій фазі. Досягнення стану насичення означає початок утворення диспергованої газової фази. Поступово, з часом, ця зона зростає і нарешті відповідає повній висоті тепер уже газорідинного середовища. Оскільки нижні шари останнього знаходяться під дією суми зовнішнього і гідростатичного тисків, то із заглибленням в газорідинну фазу стала насичення зростає, а 3 нею і градієнт концентрацій. За відсутності вертикальної циркуляції таке співвідношення було б статичним і не на користь процесу бродіння, бо значення $c_{\text {н }}=$ const відповідає опору масопередачі на межі поділу поверхні контактування між дріжджовими клітинами і рідинною фазою.
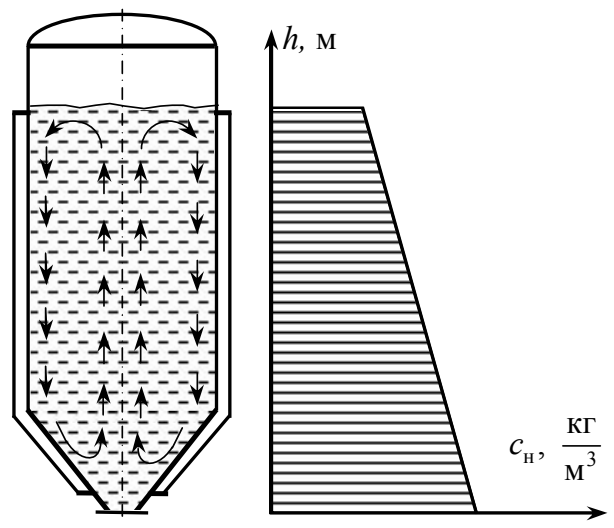

Рис. 2. Схема основного циркуляційного контуру бродильного апарата

Єдиною технічною можливістю вивести середовище з такого колапсового стану є збільшення тиску в системі. Однак очевидно, що цей показник має обмеження, у зв'язку з чим доцільно стати на шлях змінних тисків у газовому надрідинному об'ємі. Відмітимо, що за таких умов показники гідростатичних тисків залишаються незмінними. Проте саме гідростатичні тиски рідинної фази у взаємодії з вертикальними циркуляційними контурами призводять до створення локальних зон, в яких формуються умови для десатурації і сатурації (рис. 2). У висхідній зоні циркуляційного контуру зниження гідростатичного тиску призводить до активної десатурації, хоча рідинна фаза про- 
довжує бути в стані насичення. 3 переходом частково десатурованої рідинної фази в опускну частину циркуляційного контуру досягається умова:

$$
c_{\mathrm{i}}<c_{\mathrm{H}},
$$

де $c_{\mathrm{i}}$ - плинне значення концентрації розчиненого $\mathrm{CO}_{2}$.

До позитивного впливу зростаючого гідростатичного тиску додається збільшення сталої насичення за показником температури, яка зменшується в локальній зоні охолодження. Наявність сорочки охолодження на конічній частині бродильного апарата у зв'язку зі збільшенням співвідношення $F_{\text {ox. }} / V_{\text {ox. }}$ (де $F_{\text {ox. }}$ та $V_{\text {ох. }}-$ відповідно, поверхня і об'єм охолодження) динаміка охолодження цієї частини середовища зростає, як і розчинність $\mathrm{CO}_{2}$, на користь зменшення опору масопередачі та загальному результату. Наведена феноменологічна модель створення зон сатурації і десатурації середовищ не лише пояснює можливість реалізації процесів бродіння в стані насичення середовищ, а й додаткового вказує на шлях детермінованих і відчутно підсилених заходів впливу за рахунок зміни тисків у надрідинних об'ємах. Це тим більш доцільно, що в завершальній стадії бродіння зі зменшенням рівня генерування $\mathrm{CO}_{2}$ газоутримувальна здатність помітно обмежується. Разом 3 нею знижується інтенсивність циркуляційних контурів, зростає концентрація розчиненого $\mathrm{CO}_{2}$ до рівня насичення, утворення зон локальної десатурації $\mathrm{i}$ сатурації не відбувається. Повернення середовища до стану продовження режиму сатурації можливе лише за рахунок підвищення тиску в газовому надрідинному об'ємі.

Детермінована система зі змінними програмованими тисками в надрідинному об'ємі має за перевагу ту обставину, що режими активної десатурації і сатурації відбуваються в повному об'ємі середовища. При цьому режим десатурації може бути достатньо швидкоплинним і обмеженим в часі, тоді як час, в якому середовище здатне до поглинання $\mathrm{CO}_{2}$, може бути більш подовженим і пов'язаним зі швидкістю його синтезу. Важливо, що швидкоплинний режим десатурації відбувається зі створенням енергетичного імпульсу на зразок того, що має місце в дискретно-імпульсних технологіях. Різке скидання тиску в обмеженому кількома секундами часі супроводжується активним утворенням диспергованої газової фази, підвищенням показника газоутримувальної здатності, енергетичним імпульсом, який супроводжується прискоренням рухомих мас у циркуляційних контурах. У першому наближенні приведену масу рідинної фази можна вважати наближеною до ії повного фізичного значення. При цьому рушійному фактору відповідає комплекс $\rho_{\text {рід.д }} g u$, який у цьому перехідному процесі буде змінним у зв'язку зі зростаючим значенням газоутримувальної здатності. Завершенню перехідного процесу відповідає досягнення планового мінімального тиску і максимальної величини $u_{\max }$. Величина енергетичного імпульсу і рівень вилучення розчиненого $\mathrm{CO}_{2}$ визначаються перепадами тиску $\Delta P$, за якого маса вилученого $\mathrm{CO}_{2} 3$ кожної одиниці об'єму рідинної фази складе:

$$
m_{\mathrm{CO}_{2}}=k \Delta P, \kappa \Gamma / \mathrm{M}^{3}
$$


і, відповідно, з повного об’єму рідинної фази:

$$
m_{\mathrm{CO}_{2}}^{\prime}=k \Delta P V_{\text {рід. }}, \text { кг. }
$$

Важливо, що на величину десатурації гідростатичний тиск не впливає i при цьому сатураційні можливості середовища, пов'язані з подальшим підвищенням тиску у системі, також не залежать від гідростатичного тиску.

Подальше зростання сатураційної здатності також пов'язане з діапазоном подальшого підвищення тиску $\Delta P$. Оскільки в режимі десатурації середовище продовжує перебувати в стані насичення, то це також є однією з причин його швидкоплинного перебігу. Перехідний процес підвищення тиску також доцільно мати швидкоплинним, тому об'єм газового надрідинного середовища має бути якомога меншим.

Змінні значення тисків мають додаткове фізико-хімічне супроводження, пов'язане зі змінами осмотичних тисків. Відповідно до принципу суперпозиції осмотичні тиски в зброджуваних середовищах утворюються розчиненими цукром, етиловим спиртом і діоксидом вуглецю. Від початку бродіння найбільша частка осмотичного тиску належить розчиненому цукру, а в міру перебігу процесу ця складова зменшується, а складова по спирту зростає зі збільшенням його концентрації аж до рівня критичної. Очевидно, що осмотичні тиски, які створюються діоксидом вуглецю, обмежуються його розчинністю, а залежність останньої від тиску в системі приводить до висновку про можливість осциляцій осмотичних тисків по цій складовій, оскільки це не стосується змін концентрацій інших розчинених речовин.

Звідси приходимо до висновку, що зниження тиску і десатурація синхронно знижують осмотичний тиск. Це означає можливість швидкоплинних змін останнього. Тож режим десатурації середовищ має потрійний позитивний ефект, створюваний енергетичним імпульсом зі зростаючою газоутримувальною здатністю, зниженням концентрації $\mathrm{CO}_{2}$ зі зменшенням опору масопередачі і зниженням осмотичного тиску. Позитивом режиму сатурації $\epsilon$ переведення середовища до стану ненасичення зі зменшенням опору масопередачі. Однак відсутність процесу синтезу диспергованої газової фази при цьому слід віднести до негативного прояву, в часі існування якого циркуляційний контур буде створюватись лише за рахунок ефекту охолодження середовища.

\section{Висновки}

1. Розроблені математичні формалізації стосуються взаємозв'язків між динамікою зброджування цукрів, газоутворенням, гідродинамічними параметрами диспергованої газової фази, енергетичними потенціалами газового середовища, диспергованої газової фази і розчиненого $\mathrm{CO}_{2}$.

2. Запропоновано рушійний фактор циркуляційних контурів визначати за величиною газоутримувальної здатності на основі третього закону Ньютона i закону Архімеда.

3. Показано наявність взаємозв'язків між геометрією середовищ і газоутримувальною здатністю у випадках систем 3 анаеробним генеруванням газової фази. 
4. Розчинений діоксид вуглецю в культуральному середовищі має подвійну негативну дію. По-перше, в сукупності з розчиненими цукром і етиловим спиртом він створює свою частку осмотичного тиску, наближаючи систему до бактеріостатичного стану. По-друге, антимікробна дія пов'язана 3 приведенням рідинної фази до стану насичення на $\mathrm{CO}_{2}$, за якого опір масопередачі зростає до критичного рівня.

5. Десатурація середовища забезпечує обмеження осмотичних тисків за рахунок зниження фізичних тисків у середовищі, а подальше примусове підвищення їх забезпечує поновлення режиму сатурації та інтенсифікацію масообміну по $\mathrm{CO}_{2}$.

\section{Лiтература}

1. Пирог Т.П. Загальна біологія. Київ: НУХТ, 2010. 632 с.

2. Губський Ю.Г. Біоорганічна хімія: підручник. Київ-Вінниця: Нова книга, 2007. 432 с.

3. Тиманюк В.А., Животова Е.Н. Биофизика. Київ: Професіонал, 2004. 704 с.

4. Енергетичні потенціали газорідинних середовищ / Соколенко А.І. та ін. Наукові праиі Наиіонального університету харчових технологій. 2018. Т. 24, № 1. С. 102-118.

5. Соколенко А.І., Шевченко О.Ю., Піддубний В.А. Інтенсивні технології харчових виробництв. Харчова і переробна промисловість. 2008. № 4. С. 25-28.

6. Шевченко О.Ю.Динаміка перехідних процесів у системах анаеробного бродіння. Наукові прачі Наиіонального університету харчових технологій. 2017. Т. 23, № 6. С. 68-76.

7. Effect of turbulence on particle and bubble slip velocity // Chemical Engineering Science Volume 100, 30 August 2013, P. 120-136. URL: https://www.sciencedirect.com/science/article/pii/S0009250913002133 (дата звернення 20.09.2018).

8. A porous media model for CFD simulations of gas-liquid two-phase flow in rotating packed beds. Chemical Engineering Science Volume 189, 2 November 2018, P. 123-134. URL: https://www.sciencedirect.com/science/article/pii/S0009250918302902 (дата звернення 02.10.2018).

9. Кунце В. Технология солода и пива. Санкт-Петербург: Профессия, 2001. 912 с. 